\title{
АВТОМАТИЗИРОВАННОЕ РАБОЧЕЕ МЕСТО АДМИНИСТРАТОРА ОПЕРАТИВНОЙ ДЕЖУРНОЙ СМЕНЫ ЦЕНТРА УПРАВЛЕНИЯ В КРИЗИСНЫХ СИТУАЦИЯХ
}

\author{
А. Л. Попов \\ Государственное казенное учреждение города Москвы «Пожарно-спасательный центр»
}

Поступила в редакцию 09.06.2019 г.

\begin{abstract}
Аннотация. Статья посвящена реализации процесса поэтапного перехода к интеллектуальной и технической поддержке деятельности оперативной дежурной смены регионального Центра управления в кризисных ситуациях МЧС России. В статье реализована идея разработки автоматизированного рабочего места администратора оперативной дежурной смены. Разработаны программные модули интерфейсов информационных блоков. Применены оригинальные авторские алгоритмы: объединения данных, генерации реквизитов документов, передачи информации между автоматизированными рабочими местами, фиксирования и контроля времени готовности документов, доступа к необходимой справочной информации, прогнозирования вероятности риска, анализа фактов и результатов предупреждения возможного возникновения чрезвычайных ситуаций (происшествий) и пожаров.

Ключевые слова: антикризисное управление, интеллектуальная поддержка, система управления базами данных, техническая поддержка, чрезвычайная ситуация, центр управления в кризисных ситуациях.
\end{abstract}

\section{ВВЕДЕНИЕ}

Детальное изучение научных работ посвящённые моделям и алгоритмам обеспечения антикризисного управления с участием должностных лиц (руководителей и специалистов) Центра управления в кризисных ситуациях (ЦУКС) МЧС России позволяет реализовать поэтапный процесс перехода к интеллектуальной и технической поддержке деятельности оперативной дежурной смены (ОДС) регионального ЦУКС с точки зрения идентификации, оценки и управления рисками автоматизированного процесса подготовки документов для Национального Центра управления в кризисных ситуациях (НЦУКС) [1] [2]. В основу формирования этой точки зрения положены «Методики оценки рисков чрезвычайных ситуаций и нормативы приемлемого риска чрезвычайных ситуаций» [3]. Этапы данного процесса представлены на рис. 1 [4].

() Попов А. Л., 2019

\section{ВЫЯВЛЕНИЕ И АНАЛИЗ ПРОБЛЕМНЫХ ВОПРОСОВ}

На первом этапе определена зависимость эффективности работы ОДС от результатов выявления и анализа проблемных вопросов [5] и зависимых рисков на основании планируемых и фактических показателей регламентированной деятельности руководителей и специалистов ОДС регионального ЦУКС [6] в части представления в НЦУКС МЧС России донесений (докладов) по реагированию на чрезвычайную ситуацию (ЧС), происшествие или пожар (табл. 1.).

Исходя из представленных планируемых и фактических показателей сделан вывод, что реально один руководитель или специалист ОДС в течение суточного дежурства может подготовить донесения (отчетные документы) в процессе реагирования на 9 ЧС (происшествий) или на 11 пожаров (для большего количества его ресурса уже недостаточно) при среднем количестве регистрируемых в сутки событий (происшествий и пожаров) равном 218. 


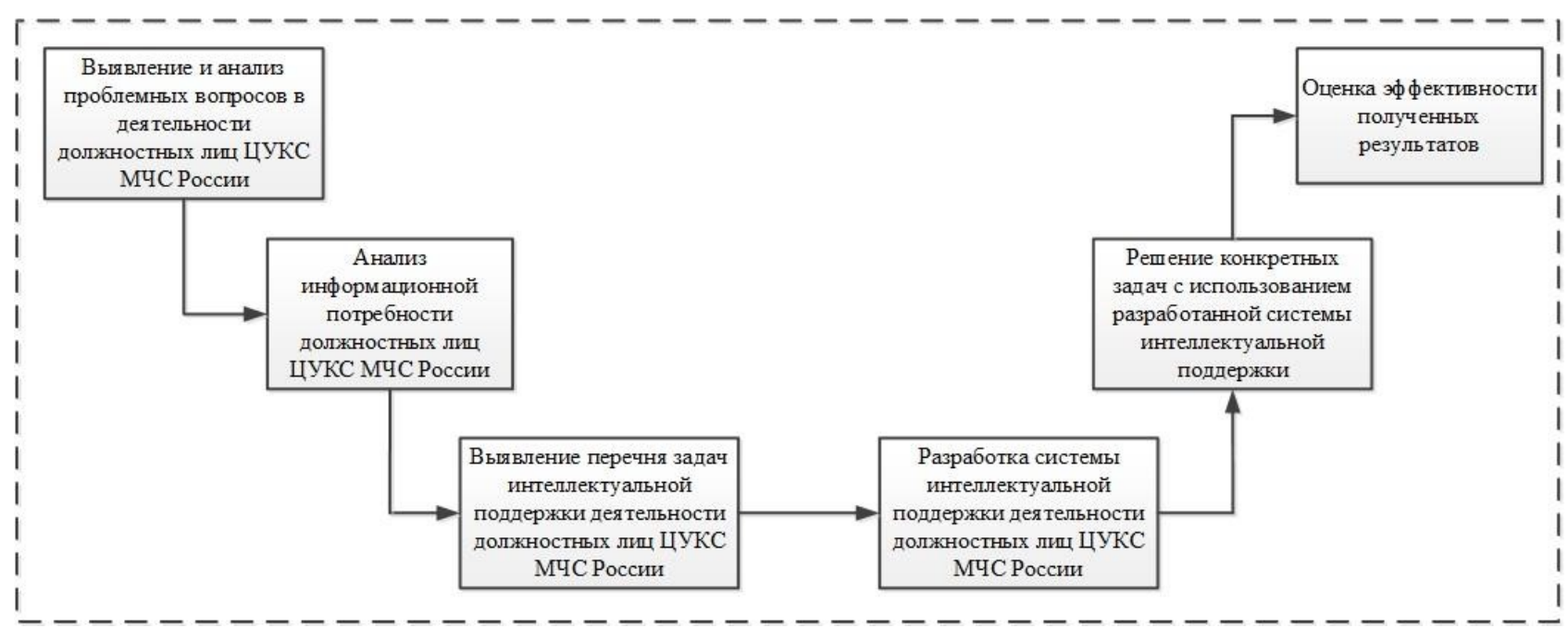

Рис. 1. Этапы перехода кинтеллектуальной поддержке

Таблица 1

Основные планируемые и фактические показатели регламентированной деятельности руководителей и специалистов ОДС ЦУКС

\begin{tabular}{|c|c|c|c|c|c|c|}
\hline $\begin{array}{c}\text { Вид } \\
\text { деятельности }\end{array}$ & Регламент & $\begin{array}{c}\text { Руководитель / } \\
\text { Специалист } \\
\text { подразделения } \\
\text { ОДС } \\
\end{array}$ & $\begin{array}{l}\text { Количество } \\
\text { документов }\end{array}$ & $\begin{array}{c}\text { Затраты } \\
\text { времени } \\
\text { (мин.) }\end{array}$ & $\begin{array}{c}\text { Трудоемкость } \\
\text { (мин./док.) }\end{array}$ & $\begin{array}{c}\text { \% загрузки } \\
\text { за сутки }\end{array}$ \\
\hline $\begin{array}{l}\text { При возникновении } \\
\text { ЧС (происшествия) }\end{array}$ & $\begin{array}{l}\text { Представление в НЦУКС } \\
\text { донесений (докладов) } \\
\text { по реагированию на ЧС } \\
\text { (происшествие) }\end{array}$ & $\begin{array}{l}\text { В среднем на } \\
\text { одного } \\
\text { специалиста }\end{array}$ & 3 & 122 & 54 & $8,47 \%$ \\
\hline \multicolumn{4}{|c|}{ Реагирование и ликвидация в сутки ЧС (происшествий) = } & \multicolumn{2}{|l|}{ 3a } & часов \\
\hline $\begin{array}{l}\text { При возникновении } \\
\text { пожара }\end{array}$ & $\begin{array}{l}\text { Представление в НЦУКС } \\
\text { донесений (докладов) по } \\
\text { пожарам }\end{array}$ & $\begin{array}{l}\text { В среднем на } \\
\text { одного } \\
\text { специалиста }\end{array}$ & 2 & 107 & 53 & $7,45 \%$ \\
\hline \multicolumn{3}{|c|}{ Реагирование в сутки при возникновении пожаров = } & 11 & 3a & \multicolumn{2}{|c|}{19,2 часов } \\
\hline $\begin{array}{l}\text { Ежедневные } \\
\text { донесения }\end{array}$ & $\begin{array}{l}\text { Представление в НЦУКС } \\
\text { ежедневных донесений } \\
\text { (докладов) }\end{array}$ & $\begin{array}{l}\text { В среднем на } \\
\text { одного } \\
\text { специалиста }\end{array}$ & 5 & 287 & 60 & $19,91 \%$ \\
\hline \multicolumn{4}{|c|}{ Ежедневные донесения в сутки подготовка } & \multicolumn{2}{|l|}{$\mathbf{3 a}$} & часа \\
\hline
\end{tabular}

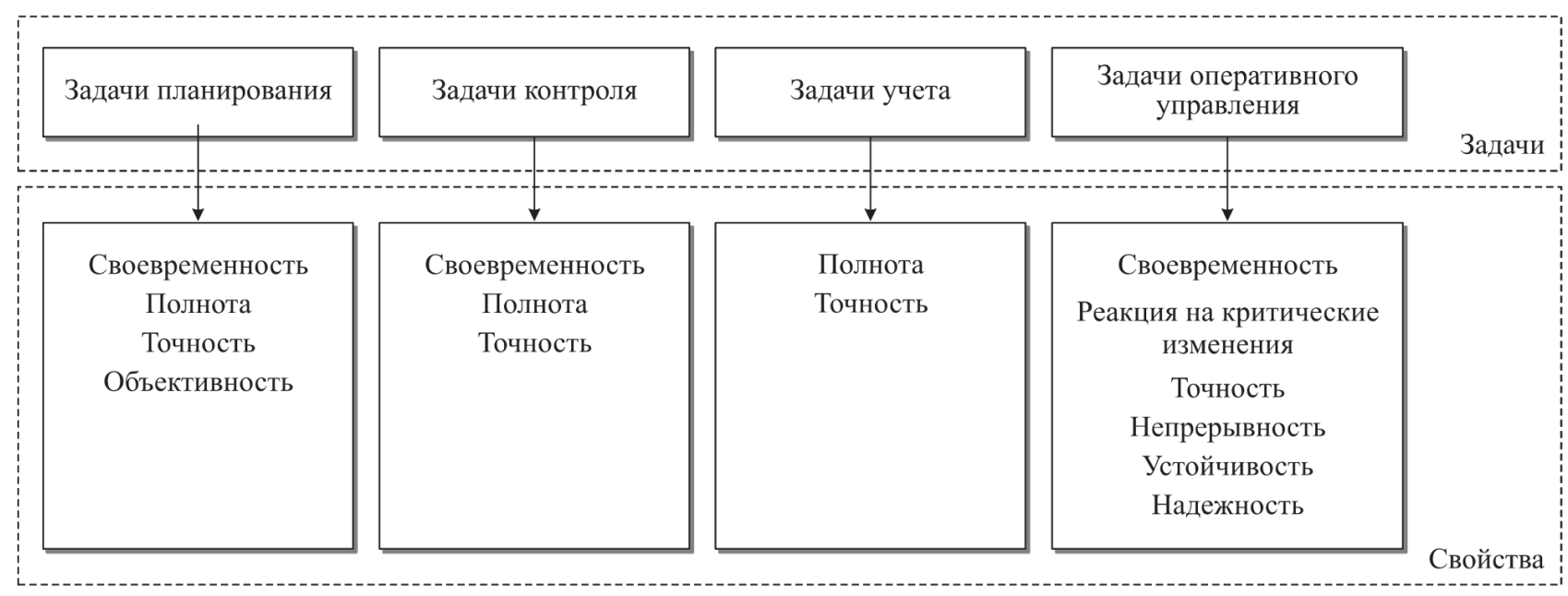

Рис. 2. Совокупность свойств для задач, распределенных по функциям управления 


\section{А. Л. Попов}

В совокупности донесения (доклады) представляемые ОДС ЦУКС в НЦУКС в процессе реагирования на ЧС (происшествия), пожары и в повседневной деятельности имеют важное значение для эффективного решения оперативных задач с учетом свойств, распределенных по функциям управления (рис. 2) [7].

Донесения являются важными информационными документами, определяющими основные этапы анализа риска ЧС и непосредственно влияют на выявление и анализ опасностей ЧС. На основе информации в донесениях разрабатываются рекомендации и меры по предупреждению, локализации и ликвидации ЧС [8]. Таким образом достоверность и актуальность информации в донесениях, предоставляемых ОДС регионального ЦУКС в НЦУКС непосредственно влияют на идентификацию, оценку и управление рисками в процессе реагирования на ЧС (происшествия), пожары.

\section{АНАЛИЗ ИНФОРМАЦИОННОЙ ПОТРЕБНОСТИ}

На втором этапе, по результатам выявления и анализа проблемных вопросов, определена информационная потребность руководителей и специалистов ОДС [9] для увеличения возможности реагирования на большее число ЧС (происшествий) или пожаров. На этом этапе проанализированы нижеследующие проблемные вопросы, решение которых влияют на снижение трудоемкости в процессе подготовки и контроля документов специалистами.

Не организована интеллектуальная и техническая поддержка деятельности руководителей и сотрудников ОДС в процессе реагирования на ЧС (происшествия), пожары.

Для организации процесса прогнозирования происшествий, чрезвычайных ситуаций (ЧС) и пожаров, их возможных социальных и экономических последствий требуется разработка новых научных методов и алгоритмов мониторинга и анализа фактов произошедших происшествий (ЧС) и пожаров с точки зрения частотного анализа повторяемости возникно- вения аналогичных событий с учетом временных периодов и территориальных зон.

Для организации процесса руководители подразделений ОДС ежемесячно в текстовом шаблоне формируют проекты графиков дежурств своих подразделений на следующий месяц, которые необходимо включать в общий «график дежурства ОДС». Такая операция может многократно повторяться при внесении необходимых изменений.

В отчетных документах обязательно присутствуют однообразные реквизиты руководителя и ответственного исполнителя (Фамилия Имя Отчество, должность, звание, телефон для связи) соответствующие данным «графика дежурства ОДС». Эти данные указываются в текстовом шаблоне каждого отчетного документа после сверки с изменениями в «графике дежурства ОДС».

В течение суточного дежурства руководитель и специалист обязаны периодически затрачивать время на ручное заполнение оперативной информацией «Журнала несения дежурства» в течение месяца по шаблону. В данном шаблоне также необходимо указывать ежесуточные реквизиты руководителя и ответственного исполнителя. Необходимая актуальная информация не может быть автоматически обработана для последующего анализа, контроля, применения и вручную дублируется на последующие сутки.

Сотрудник обязан своевременно представлять отчетные документы непосредственному руководителю на контроль, как по времени готовности по регламенту, так и по соответствию шаблону и необходимому содержанию.

Процесс подготовки руководителем или специалистом документа, как правило, требует многократного поиска и обращения к различной оперативной и справочной информации, распределенной в базах данных, информационных системах, справочниках на нескольких информационных серверах.

Перечисленные результаты анализа вызывают проблемные вопросы, которые увеличивают временные затраты и трудоемкость процесса и, как следствие, снижают эффективность и качество деятельности специалистов 
подразделений ОДС. Указанные, проблемные вопросы, к сожалению, не могут быть решены посредством действующей в региональном ЦУКС МЧС России автоматизированной системы оперативного реагирования, т. к. функции такой системы не поддерживают процессы подготовки документов сотрудниками подразделений ОДС.

\section{ВЫЯВЛЕНИЕ ПЕРЕЧНЯ ЗАДАЧ}

На третьем этапе по методике [10] выявлены основные задачи интеллектуальной и технической поддержки действующих автоматизированных рабочих мест (APM) в составе системы управления базами данных (СУБД) «АРМы ОДС»:

- автоматизация процесса интеллектуальной и технической поддержки пользователей, периодического контроля, актуализации и корректировки данных СУБД «АРМы ОДС», формирования, корректировки и информа- ционного анализа структуры баз данных (БД) СУБД «АРМы ОДС», обеспечения доработки действующих и разработки «новых» АРМ ОДС ЦУКС в соответствии с должностными и функциональными обязанностями пользователей АРМ.

- техническая поддержка процесса подготовки и контроля документов на основании рекомендаций и образцов отчетных и функциональных документов, в т. ч. отказ от дублирования и последующего редактирования ранее подготовленных однотипных документов;

- разработка новых научных методов и алгоритмов мониторинга и анализа фактов произошедших происшествий (ЧС) и пожаров для прогнозирования вероятности возникновения рисков ЧС с точки зрения частотного анализа повторяемости возникновения аналогичных событий с учетом временных периодов и территориальных зон [11] [12], по методике составления и представления различных вариантов прогноза и анализа фактов

\section{Прогнозирование событий по выбранному варианту детализации и заданным: временному периоду, территориальному признаку}

Прогнозируемое количество событий

$$
N \text { пс }=\frac{\sum N \mathrm{c}}{T n}
$$

Прогнозируемая вероятность

(\%) возникновения событий

$$
V \Pi \mathrm{C}=100 \times \frac{N \Pi \mathrm{c}}{\sum N \mathrm{c}}
$$

Анализ фактов возникновения событий по выбранному варианту детализации и заданным: временному периоду, территориальному признаку

Факт (\%) возникновения событий

$F \phi c=100 \times \frac{N \phi c}{\sum N \mathrm{c}}$
Сравнительный анализ прогноза и фактов возникновения событий по выбранному варианту детализации и заданным: временному периоду, территориальному признаку

Результат (\%) - доля не возникших из прогнозируемых событий

$$
R \mathrm{HC}=100 \times\left(1-\frac{N \phi c}{N \Pi c}\right)
$$

где: $\sum N \mathrm{c}$ - общее количество событий, зафиксированных за период с 2006 г. по настоящее время; $\mathrm{Tn}-$ количество временных периодов (час, день месяца, день недели, месяц года) в составе периода с 2006 г. по настоящее время; $\boldsymbol{N}$ п - прогнозируемое количество событий; $\boldsymbol{N \phi c}$ - фактическое количество событий; $\boldsymbol{V}$ пс - прогнозируемая вероятность (\%) возникновения событий; $\boldsymbol{F} \phi \mathbf{c}-$ факт (\%) возникновения событий; $\boldsymbol{R}$ нс - результат (\%) - доля не возникших из прогнозируемых событий.

Рис. 3. Методика составления и представления различных вариантов прогноза и анализа фактов возникновения происшествий (ЧС) и пожаров 


\section{А. Л. Попов}

возникновения происшествий (ЧС) и пожаров (рис. 3).

- автоматизация методики обеспечения руководящего контроля отчетных документов, включая время готовности по регламенту, соответствие шаблону и необходимому содержанию;

- оптимизация многократного поиска и обращения к различной оперативной и справочной информации, распределенной в базах данных, информационных системах, справочниках на нескольких информационных серверах.

\section{РАЗРАБОТКА СИСТЕМЫ ИНТЕЛЛЕКТУАЛЬНОЙ ПОДДЕРЖКИ}

На четвертом этапе реализована идея разработки АРМ администратора ОДС («АРМ Администратор») в составе СУБД «АРМы ОДС» [13] с целью снижения риска принятия необоснованных решений в условиях ЧС природного и техногенного характера.

Анализ научной литературы в области разработки методов и алгоритмов информа- ционных систем автоматизации деятельности ОДС ЦУКС МЧС России [14] [15] подтверждает, что на сегодня подобной информационной структуры и опыта функционирования такой системы применительно к регионам России, к сожалению - нет, требования к такой системе также не сформулированы.

Разработанная автором СУБД [16] не имеет аналогов как в части целевого назначения, так и в части примененных методов и алгоритмов распределения данных в комплексе AРM, а именно: хранения и применения в структурированных архивах баз данных (БД) информации о составе и основных функциях ОДС, подготовки данных для отчетных документов и реализации аналитической схемы автоматизированного документооборота ОДС ЦУКС. Такая система интеллектуальной поддержки преимущественно ориентирована на расширение возможности документального обеспечения аварийно-спасательных и других неотложных работ при происшествиях (ЧС) и пожарах и предназначена для оказания интеллектуальной поддержки руководителей и исполнителей при выполне-

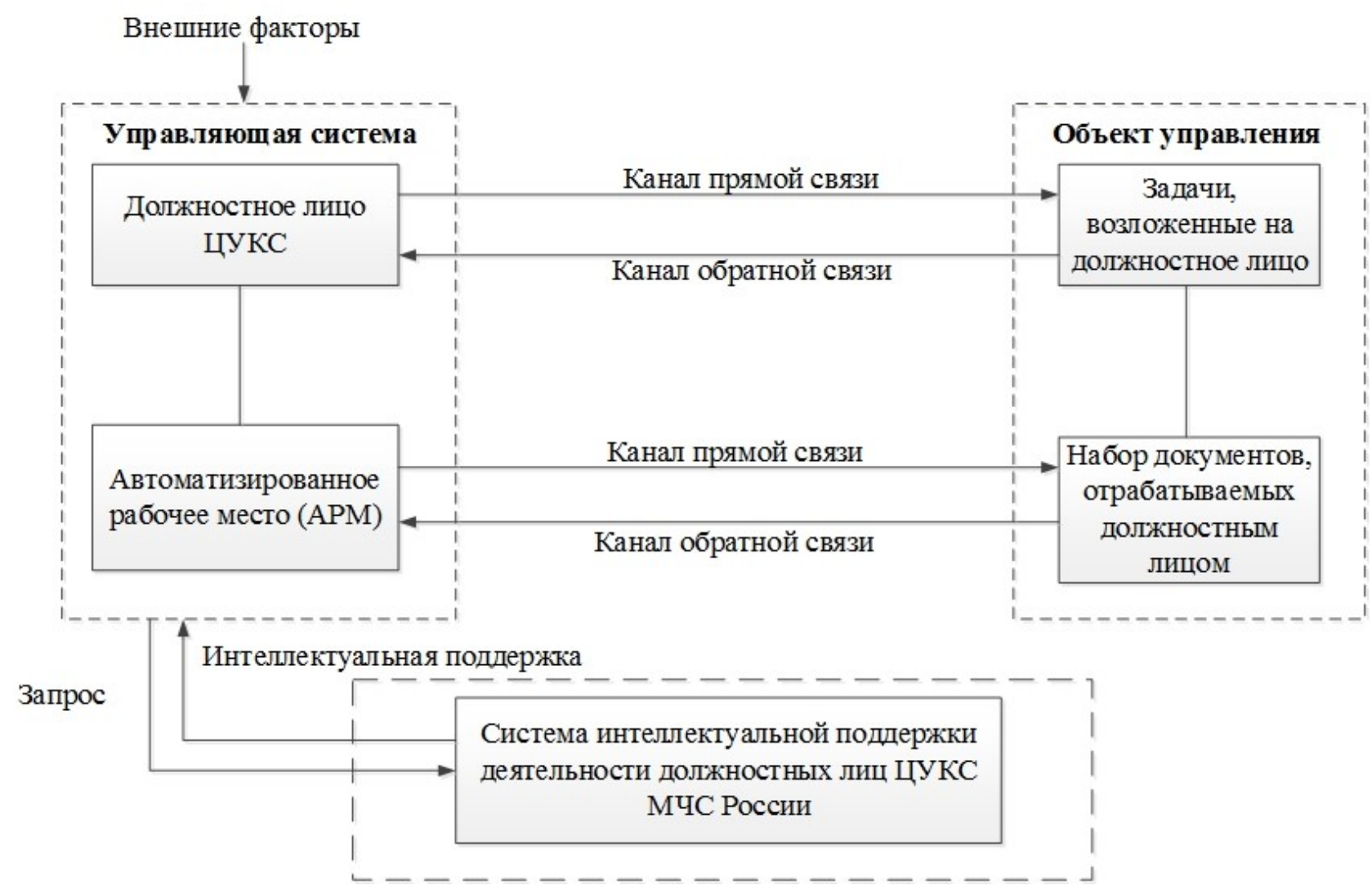

Рис. 4. Взаимодействие управляющей системы с системой интеллектуальной поддержки 


\section{АРМ Администратора ОДС ЦУКС}

нии своих функциональных обязанностей в автоматизированном процессе подготовки отчетных документов при возникновении ЧС (происшествий), пожаров и функциональных документов в режиме повседневной деятельности [17].

Взаимодействие должностного лица ОДС ЦУКС с системой интеллектуальной поддержки представлено на рис. 4. Должностные лица осуществляют свою деятельность согласно функциональным обязанностям, утвержденным приказами об оперативном реагировании ЦУКС МЧС России по субъектам Российской Федерации и региональным центрам МЧС России. Функции реализуются задачами ОДС. Управляющие воздействия должностные лица ОДС ЦУКС направляют на решение поставленных задач. Задачам соответствуют документы реагирования на происшествия (ЧС) или пожары, а также повседневные документы. «АРМ - Администратор» в качестве системы интеллектуальной поддержки осуществляет помощь как в решении частных задач, так и в разработке отдельных документов.

Для реализации «АРМ - Администратор» разработаны новые научные методы и алгоритмы следующих процессов.

- Контроль, актуализация и корректировка данных в аналогах информационных блоков АРМ пользователей (рис. 5, рис. 6).

\begin{tabular}{|c|c|c|}
\hline Виды объектов & & $\ll$ \\
\hline Поuck... & & م \\
\hline АИУС (Архив) & $\approx$ & $\Delta$ \\
\hline АРМ №1 (СОД) & $\approx$ & \\
\hline АРМ №2 (НС ОДС) & $\approx$ & \\
\hline АРМ №3 (ПСОД) & $\approx$ & \\
\hline АРМ №4 (ПСОД по ПС) & $\approx$ & \\
\hline АРМ №5 (ПСОД по СМИ) & $\approx$ & \\
\hline АРМ №6 (СпоУСиКзаОсП) & $\approx$ & \\
\hline АРМ №7 (Ст. Аналитик) & $\approx$ & \\
\hline АРМ №8 (Спец по ГИС) & $\approx$ & \\
\hline АРМ №9 (Аналитик) & $\approx$ & \\
\hline АРМ №10 (Ст тех смены) & $\approx$ & \\
\hline АРМ №11 (Техник программист) & $\approx$ & \\
\hline АРМ №12 (Спец проводной связи) & $\approx$ & \\
\hline АРМ №13 (Спец по радносвязи) & $\approx$ & \\
\hline АРМ №14 (Деж смены УМЛК и ПЧС) & $\approx$ & \\
\hline АРМ №15 (Нач ДС СПт ФПС) & $\approx$ & \\
\hline
\end{tabular}

Рис. 5. Аналоги инбормационных блоков АРМ пользователей (фрагмент)
Вероятность

„國 Вероятность_АИУС+КИС_уСС__HBКВ_ДМ_Адрес_Р-Отчет Запрос

„圈 Вероятность_АИУС+КИС_УСС_нНКВ_ДМ_Адрес-Отчет Запрос

„圈 Вероятность_АИУС +КИС_УСС_НВКВ_ДМ_Район_Улица_Р-Отчет Запрос

„國 Вероятность_АИУС +КИС_уСС_НВКВ_ДМ_Район_Улица-Отчет Запрос

В Вероятность_АИУС +КИС_УСС_нвКВ_ДМ-Отчет Запрос

„ Вероятность_АИУС+КИС_УСС_НВКВ_ДМ-Состав Запрос

“國 Вероятность_АИУС +КИС_УСС_нВКВ_ДМ-Т Запрос

“四 Вероятность_АИУС + КИС_уСС_нвКВ_ДМЧ_Адрес_Р-Отчет Запрос

*國 Вероятность_АИУС +КИС_усC_нвКВ_ДМЧ_Адрес-Отчет Запрос

„ Вероятность_АИУС+КИС_уСС_НВКВ_ДМЧ_Район_Улица_Р-Отчет Запрос

“國 Вероятность_АИУС +КИС_УСС_НВКВ_ДМЧ_Район_Улица-Отчет Запрос

、國 Вероятность_АИУС +КИС_УСС_нВКВ_ДМЧ-Отчет Запрос

„ Вероятность_АИУС+КИС_уСС_НВКВ_ДМ-Шапка Запрос

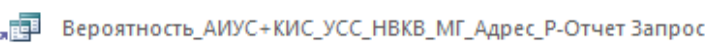

„ Вероятность_АИУС +КИС_усС_HвКВ_Mг_Адрес-Отчет Запрос

Рис. 6. Пример состава элементов аналога инбормационного блока «Вероятность» АРМ пользователя (фрагмент)

- Контроль автоматического формирования реквизитов, содержания и времени готовности документов по алгоритму:

1. Заданное время наступления события (Время Ч - Tи) - соответствует Регламенту для отчетных документов реагирования на событие.

2. Установленное время готовности документа по регламенту (По Регламенту - Тгр) соответствует Регламенту для ежедневных отчетных документов.

3. Установленная длительность подготовки документа по регламенту (Длительность Tnd) - соответствует Регламенту подготовки отчетных документов.

4. Время контроля процесса готовности документа (Время текущее - $\mathbf{T m}$ ).

5. Время начала дежурства Смены ОДС (Время Нач. Смены - Тнс).

6. Зафиксированное время готовности документа (Выполнено в - Тәд).

7. Контрольное время готовности документа (Контрольное время - Ткг):

1 вар.: Tкг $=$ Tгр или Tкг $=$ Tнс + Tид (соответственно Регламенту для ежедневных отчетных документов).

2 вар.: $\boldsymbol{T} \boldsymbol{\kappa} \boldsymbol{\imath}=\boldsymbol{T} \boldsymbol{u}+\boldsymbol{T} \boldsymbol{\eta} \boldsymbol{\partial}($ соответственно Peгламенту для отчетных документов реагирования на событие). 


\section{А. Л. Попов}

8. Прошло времени с момента начала подготовки документа (Прошло - Tnв):

1 вар.: $\mathbf{T n \boldsymbol { B }}=\mathbf{T} \boldsymbol{m}-\mathbf{T} \boldsymbol{c} \boldsymbol{c}($ соответственно Peгламенту для ежедневных отчетных документов).

2 вар.: $\mathbf{T n} \boldsymbol{\varepsilon}=\mathbf{T} \boldsymbol{m}-\boldsymbol{T} \boldsymbol{u}$ (соответственно Регламенту для отчетных документов реагирования на событие).

9. Осталось времени до контрольного времени готовности документа (Осталось - Тов): Тов $=T \kappa 2-T m$.

10. Время, затраченное на подготовку документа (Время Затрачено - T3):

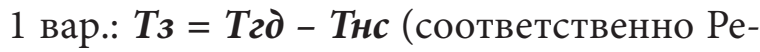
гламенту для ежедневных отчетных документов).

2 вар.: $\mathbf{T} \boldsymbol{3}=\mathbf{T} \boldsymbol{д}-\boldsymbol{T} \boldsymbol{и}$ (соответственно Регламенту для отчетных документов реагирования на событие).

11. Время, на которое просрочена готовность документа (Просрочено на - Tnz): $\operatorname{Tn} 2=T 2 \partial-T \kappa 2$.

- Доступ к различным информационным справочникам по гиперссылкам в объединенной локальной вычислительной сети (ОЛВС).

- Сервисная настройка меню интерфейса пользователя АРМ.

- Формирование, настройка и информационный анализ структуры БД СУБД «АРМы ОДС».

- Доработка действующих и разработка «новых» АРМ на основе аналогов информационных блоков АРМ пользователей.

Разработанные оригинальные научные методы и алгоритмы, необходимые для создания «АРМ - Администратор», в настоящее время очень актуальны, а опыт создания и функционирования подобного АРМ не имеет известных аналогов и применим в рамках обеспечения как интеллектуальной, так и технической поддержки деятельности ОДС ЦУКС субъекта РФ.

\section{РЕІЕНИЕ КОНКРЕТНЫХ ЗАДАЧ}

На пятом этапе решены конкретные задачи с использованием объединения аналогов программных модулей интерфейсов информационных блоков АРМ пользователей в со- ставе «АРМ - Администратор». Разработана аналитическая модель АРМ взаимодействия с распределенными базами данных для контроля изменения, поиска и фильтрации данных; предварительного просмотра, печати и сохранения контрольных документов в формате структуры и форм выбранных шаблонов.

Структура управляемых БД поддерживает новые способы хранения данных распределенных по тематическим и функциональным признакам в разных базах данных, связанных с независимыми интерфейсами АРМ, что позволяет одновременно, многократно и разнообразно интерпретировать одни и те же данные для решения различных функциональных задач в многопользовательском режиме. Примененные способы обеспечивают ряд преимуществ по сравнению с традиционными, а именно: исключается дублирование информации, поддерживается обновление и загрузка новых данных из внешних автоматизированных систем, реализуется информационный обмен между разными АРМ, обеспечивается надежность и быстродействие взаимодействия с пользователем каждого отдельного АРМ.

Структура и реализованные функции «АРМ - Администратор» в составе СУБД «АРМы ОДС» представлены на рис. 7.

Состав структуры и функций «АРМ - Администратор»:

Сервер ОЛВС (объединенная локальная вычислительная сеть).

Группы АРМ (автоматизированных рабочих мест): «ОДС», «Руководитель», «Специалист», «ОДС (01)» (службы «01»), «ОДС (ПСЦ)» (службы «Пожарно-спасательный центр» - «ПСЦ»), «Руководитель (ЦУКС)» (Центр управления в кризисных ситуациях), «Руководитель (ПСЦ)».

Функции (в составе АРМ): Техническая поддержка пользователей СУБД «АРМы ОДС» (система управления базами данных автоматизированных рабочих мест оперативной дежурной смены); Поддержка актуальности и структуры данных СУБД «АРМы ОДС»; Доработка действующих и разработка «новых» АРМ в составе СУБД «АРМы ОДС»; Формирование и корректировка: функци- 


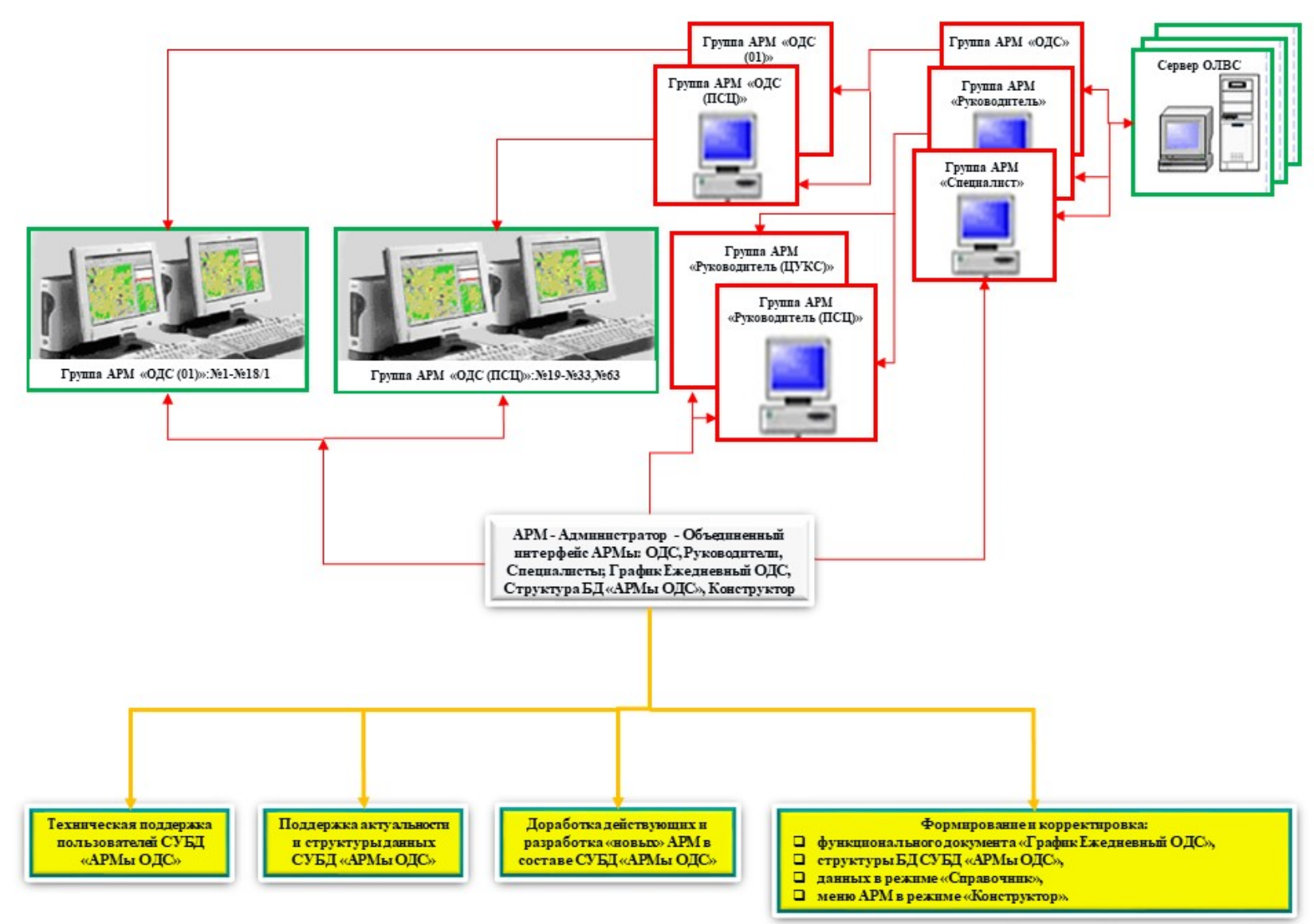

Рис. 7. Структура и функиии «АРМ - Администратор»

онального документа «График Ежедневный ОДС», структуры БД СУБД «АРМы ОДС», данных в режиме «Справочник», меню АРМ в режиме «Конструктор».

Меню операций взаимодействия с «АРМ Администратор» представлено на рис. 8.

Реализованные и объединенные аналоги интерфейсов информационных блоков АРМ пользователей являются основными компонентами функций в составе «АРМ - Администратор».

Реализованные интерфейсы информационных блоков используются для обеспечения разработанных новых методов, алгоритмов хранения и представления данных в СУБД «АРМы ОДС» и являются основными компонентами модифицируемых функций в составе конкретного АРМ руководителя или специалиста ОДС, которые позволяют модифицировать действующие и формировать новые функциональные АРМ.

Интеллектуальная поддержка предполагает оказание помощи должностному лицу в выполнении своих функциональных обя- занностей, решении задач в повседневной деятельности и в режиме чрезвычайной ситуации (ЧС) посредством удаленного взаимодействия Администратора ОДС на «АРМ Администратор» с любым АРМ Пользователя СУБД «АРМы ОДС» на уровне контроля набора документов обрабатываемых должностным лицом, анализа процесса решения задач возложенных на должностное лицо, обеспечения оптимизации и корректности решения этих задач.

Техническая поддержка (контроль действий и результатов, корректности, корректировки данных и т. п.) пользователя АРМ выполняется посредством выбора и доступа к аналогу интерфейса выбранного пользователя.

В аналоге интерфейса поддерживается выполнение следующих операций:

- контроля, ввода, изменения, поиска, фильтрации данных;

- предварительного просмотра, выгрузки в файл, печати вариантов отчетного или функционального документа; 


\section{А. Л. Попов}

Взаимодействие с «АРМ - Администратор» ОДС Запуск БД АРМ

Функции формирования и корректировки данных в информационных блоках в режиме «Функции»

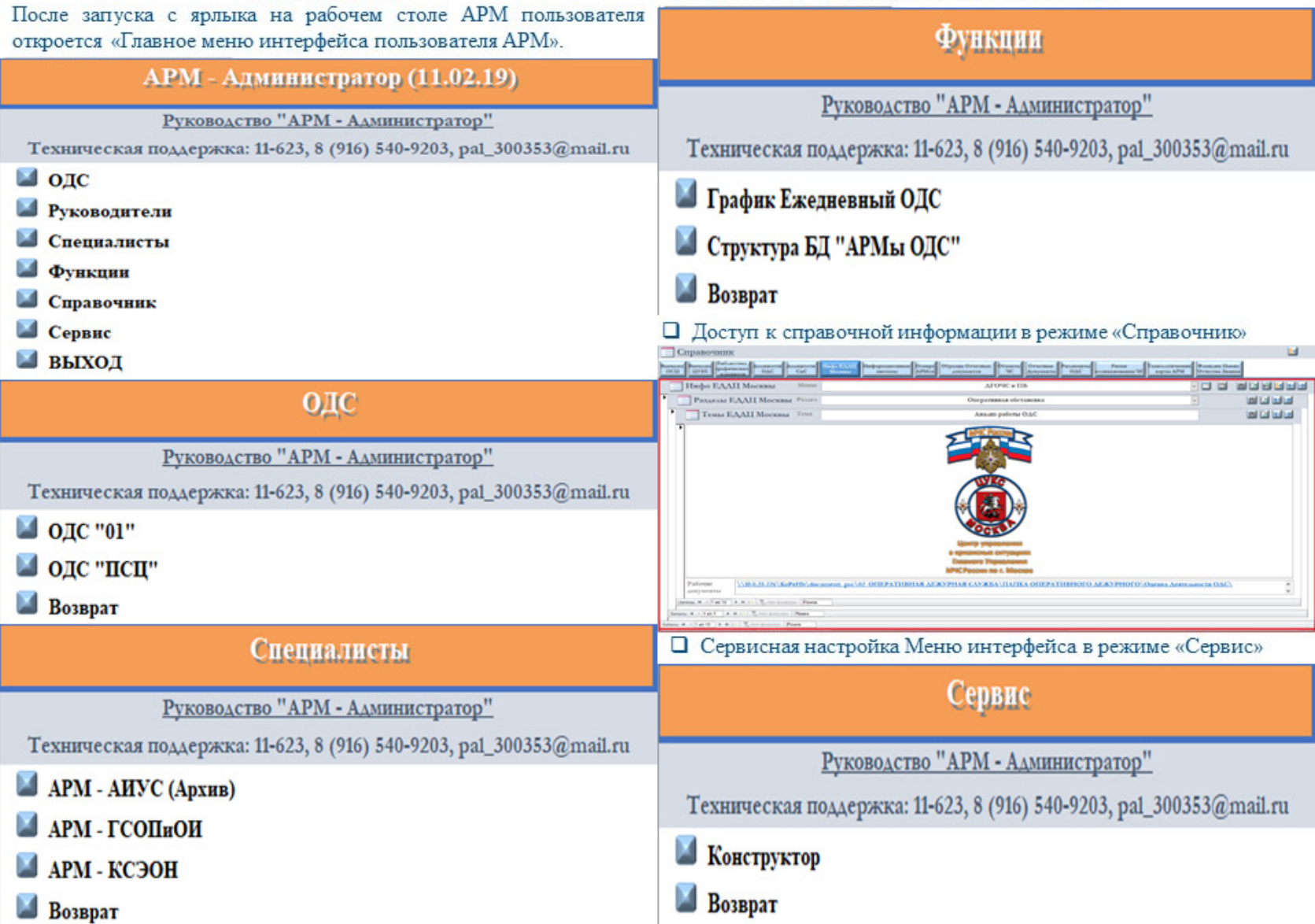

Рис. 8. Меню операиий взаимодействия с «АРМ - Администратор»

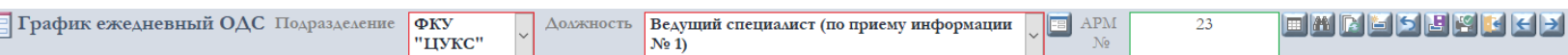

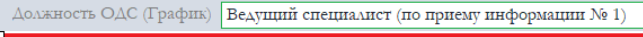

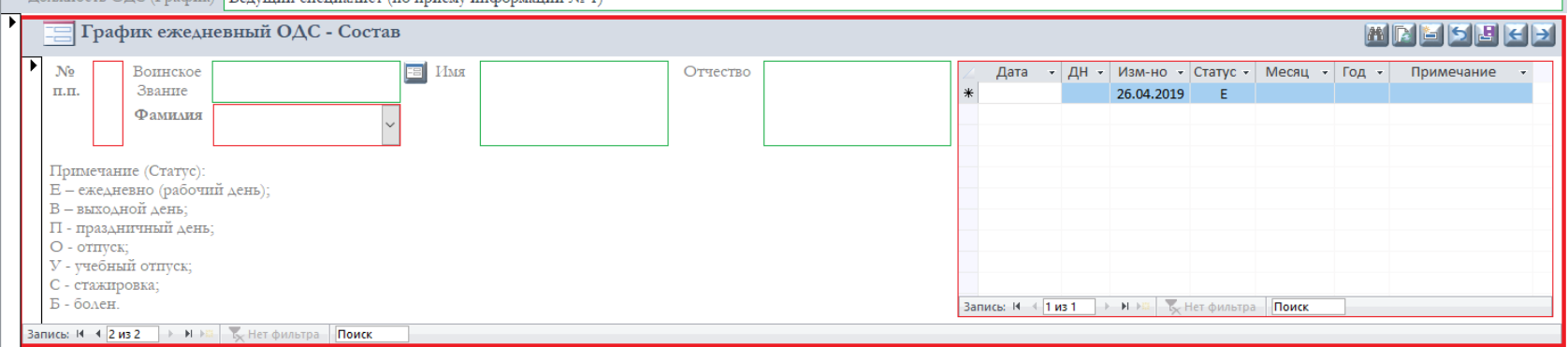

Рис. 9. Информационный блок «График Ежедневный ОДС»

- контроля времени готовности отчетного документа.

Информационный блок «График Ежедневный ОДС» (рис. 9.) реализован на базе алгоритма автоматического формирования реквизитов Функциональных документов пользователей АРМ СУБД «АРМы ОДС» (рис. 10.).

Информационный блок Структура БД «АРМы ОДС» (рис. 11.) предназначен для формирования, контроля и анализа структуры БД «АРМы ОДС».
Порядок формирования структуры БД «АРМы ОДС» предусматривает последовательное изменение и добавление данных по составу элементов БД путем заполнения и последующего выбора из справочников однотипных элементов наименований структурно связанных элементов по следующему алгоритму:

1. Выбор вкладки типа элементов структуры БД.

2. Поиск и выбор наименования элемента БД. 


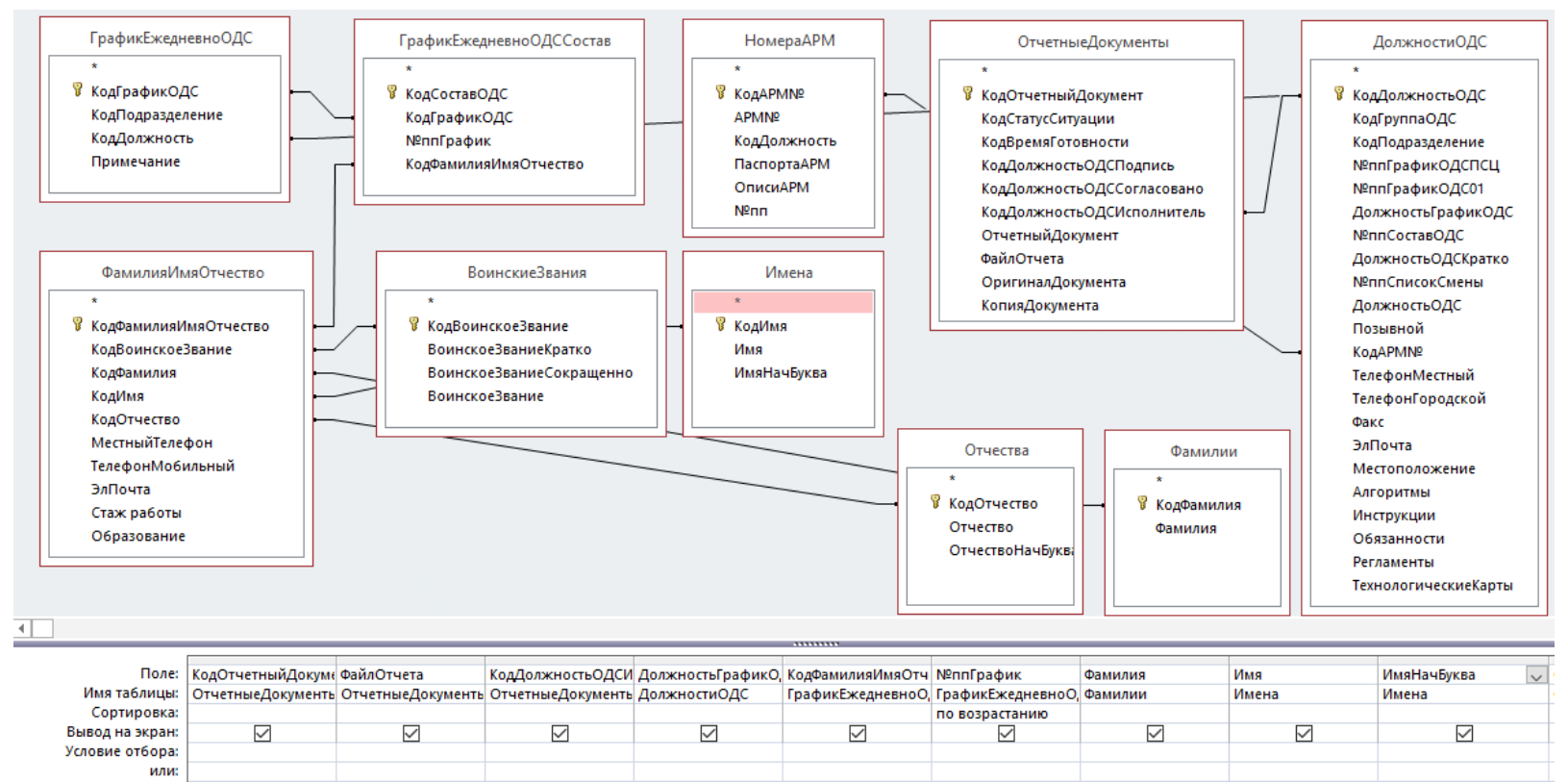

Рис. 10. Алгоритм автоматического формирования реквизитов Исполнителя

Функииональных документов пользователя АРМ СУБД «АРМь ОДС» (пример)

Структура БА "АРМы ОАС"

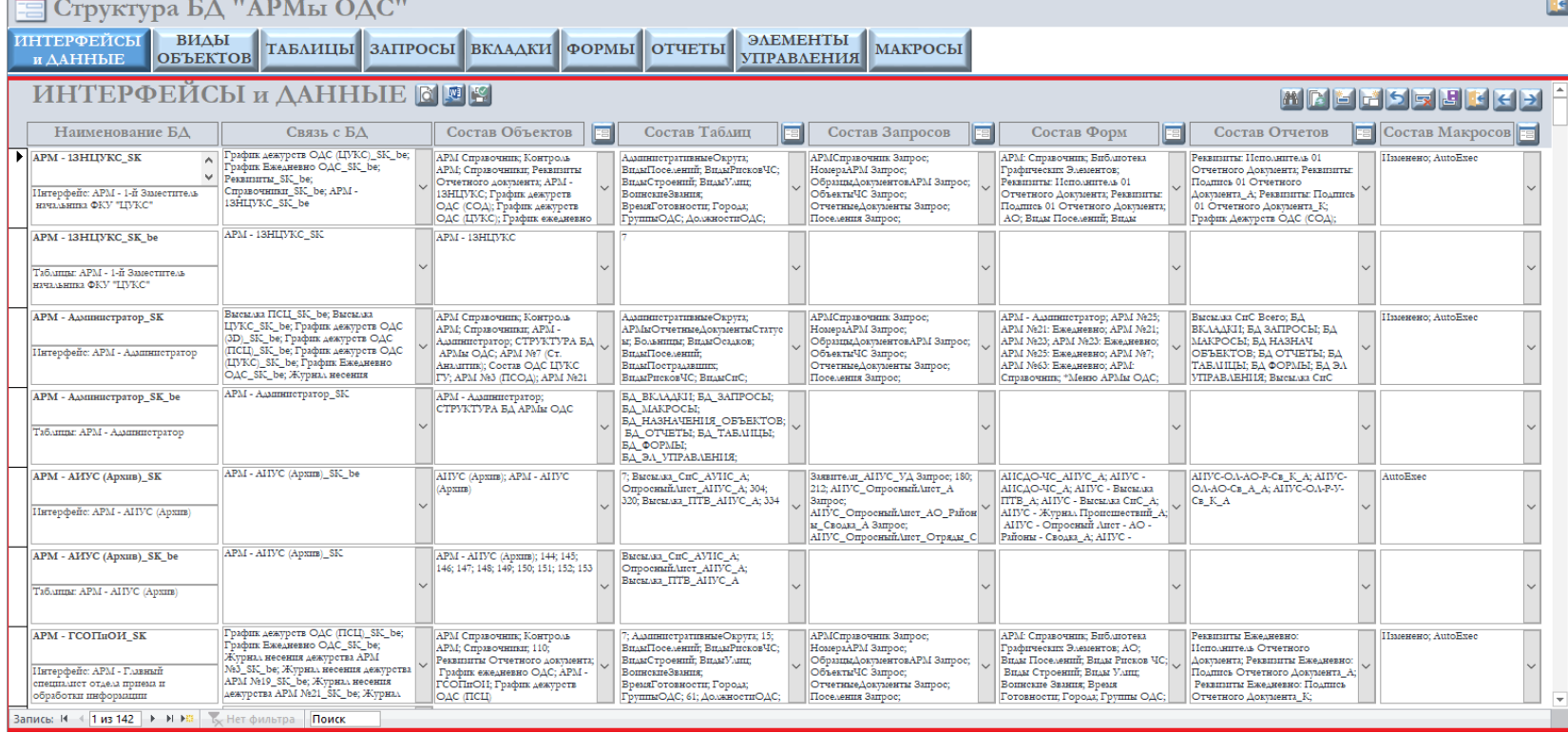

Рис. 11. Инбормационный блок Структура БД «АРМы ОДС»

3. Описание выбранного элемента БД в табличной форме путем выбора из Справочников однотипных элементов:

- элементов, связанных с выбранным элементом;

- составных элементов.

4. Контроль и анализ выбранного элемента БД в отчете (рис. 12), содержащем табличное описание (перечисление):

- элементов, связанных с выбранным элементом;

- составных элементов.
Режим «Справочник» (рис. 13.) обеспечивает доступ пользователя АРМ к различным информационным Справочникам по гиперссылкам в объединенной локальной вычислительной сети (ОЛВС), необходимым при формировании отчетных документов при происшествии, ЧС, пожаре и функциональных документов в режиме ежедневной деятельности ОДС ЦУКС.

Сервисная настройка меню интерфейса пользователя АРМ выполняется в режиме «Сервис» (рис. 14). 


\section{А. Л. Попов}

\begin{tabular}{|c|c|c|}
\hline УАБЛИЩЫ & & $\begin{array}{r}11 \text { июоля 201! } \\
21: 41\end{array}$ \\
\hline Наименование Таблицы & В Составе БД & Прямая Связь с Таблицами \\
\hline АдминистративныеОкруг а & Справочники_SK_be & $\begin{array}{l}\text { ОбъектыЧС; Районы; Сводка01_N_KИС; } \\
\text { ОтветственныеЛица; ПодключенияОСО; } \\
\text { ПодкпюченияСиреньг; ПодкпюченияУЗФ } \\
\text { УЗФ_Линии; Учет АСО_УГЗ; Учет } \\
\text { Сиреньг; УчетОКСИОН; УчетОСО }\end{array}$ \\
\hline В Составе Запросов & В Составе Форм & В Составе Отчетов \\
\hline 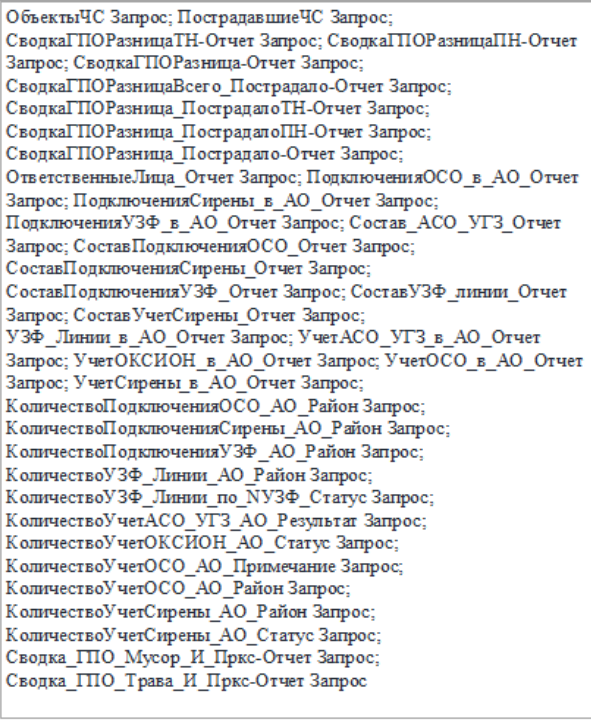 & $\mathrm{AO} ;$ Объекты ЧС & Активация Windows \\
\hline
\end{tabular}

Рис. 12. Контроль и анализ выбранного элемента БД в отчете

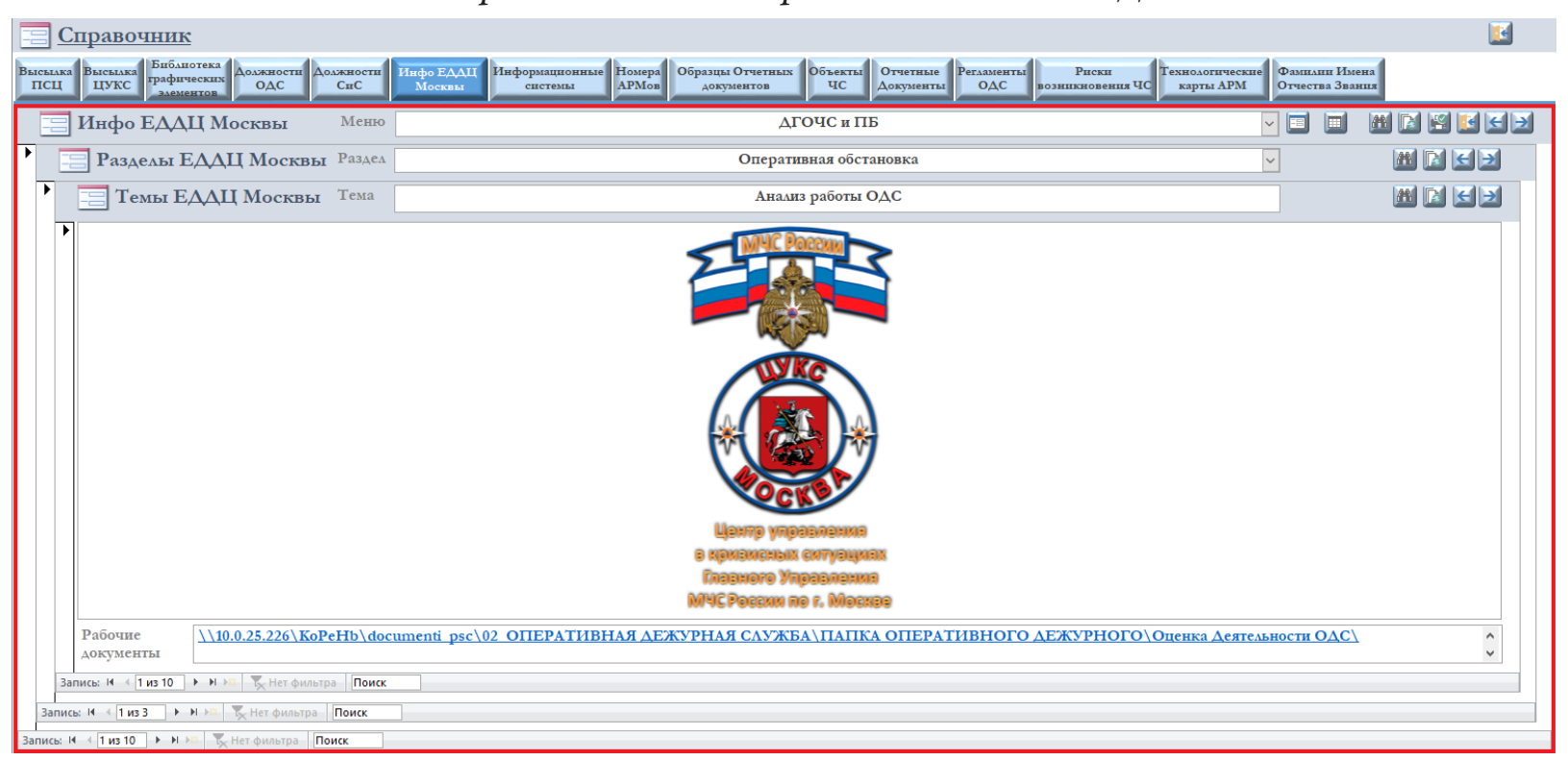

Рис. 13. Режим «Справочник»

Интерфейс любого аналога информационного блока может быть смодифицирован или доработан соответственно требованиям и перенесен в необходимый АРМ пользователя.

На базе существующего аналога информационного блока разрабатывается «новый» информационный блок для включения в состав АРМ пользователя.
Техническая поддержка «АРМ - Администратор» обеспечивается Администратором ОДС и включает обслуживание СУБД «АРМы ОДС»: организацию файловой структуры, создание страховых копий файлов, актуализацию данных. 


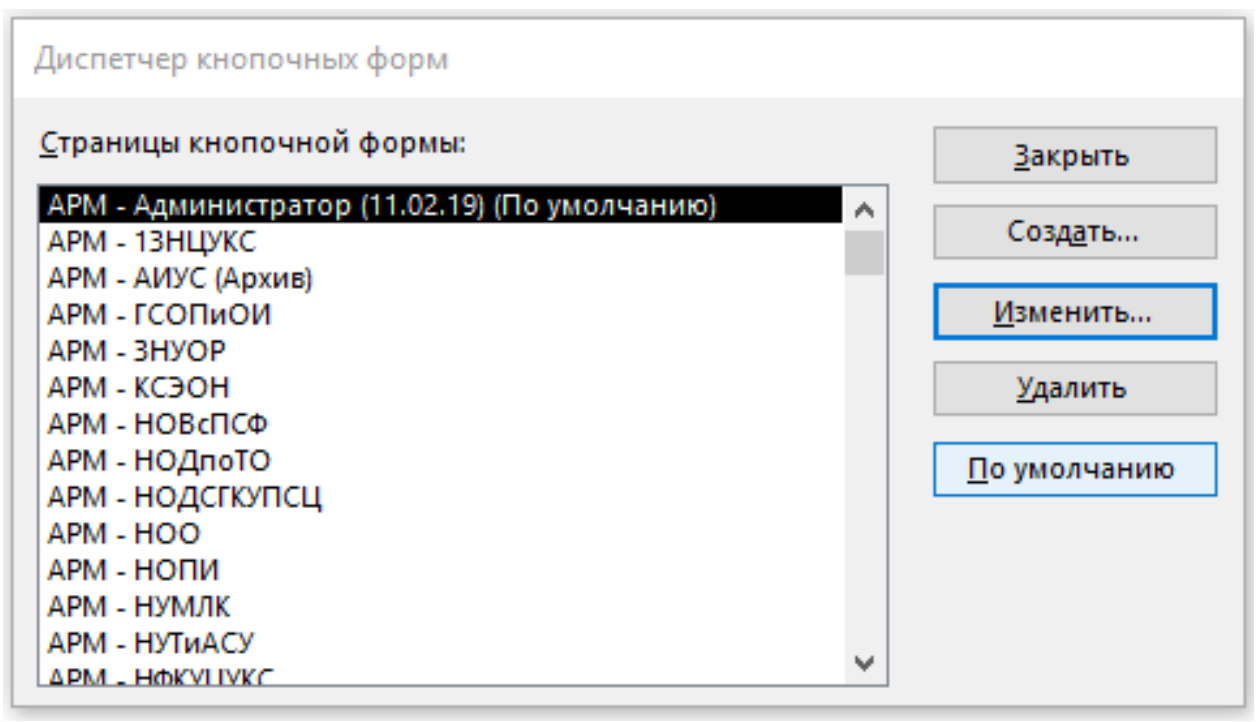

Рис. 14. Диспетчер кнопочных форм (фрагмент)

Таблица 2

Улучшение показателей процесса подготовки документов специалистами ОДС

\begin{tabular}{|c|c|c|c|c|c|c|}
\hline \multicolumn{7}{|c|}{ Показатели после внедрения АРМ «Администратор» } \\
\hline $\begin{array}{c}\text { Вид } \\
\text { деятельности }\end{array}$ & Регламент & $\begin{array}{c}\text { Руководитель / } \\
\text { Специалист } \\
\text { подразделения } \\
\text { ОДС } \\
\end{array}$ & $\begin{array}{l}\text { Количество } \\
\text { документов }\end{array}$ & $\begin{array}{c}\text { Затраты } \\
\text { времени } \\
\text { (мин.) }\end{array}$ & $\begin{array}{l}\text { Трудоемкость } \\
\text { (мин./док.) }\end{array}$ & $\begin{array}{c}\text { \% загрузки } \\
\text { за сутки }\end{array}$ \\
\hline $\begin{array}{l}\text { При возникновении } \\
\text { ЧС (происшествия) }\end{array}$ & $\begin{array}{l}\text { Представление в НЦУКС } \\
\text { донесений (докладов) } \\
\text { по реагированию на ЧС } \\
\text { (происшествие) }\end{array}$ & $\begin{array}{l}\text { В среднем на } \\
\text { одного } \\
\text { специалиста }\end{array}$ & 3 & 61 & 24 & $4,24 \%$ \\
\hline \multicolumn{4}{|c|}{ Реагирование и ликвидация в сутки ЧС (происшествий) = } & \multicolumn{2}{|l|}{ 3a } & часов \\
\hline $\begin{array}{l}\text { При возникновении } \\
\text { пожара }\end{array}$ & $\begin{array}{l}\text { Представление в НЦУКС } \\
\text { донесений (докладов) по } \\
\text { пожарам }\end{array}$ & $\begin{array}{l}\text { В среднем на } \\
\text { одного } \\
\text { специалиста }\end{array}$ & 2 & 54 & 32 & $3,72 \%$ \\
\hline \multicolumn{4}{|c|}{ Реагирование в сутки при возникновении пожаров = } & \multicolumn{2}{|l|}{ 3a } & часов \\
\hline $\begin{array}{l}\text { Ежедневные } \\
\text { донесения }\end{array}$ & $\begin{array}{l}\text { Представление в НЦУКС } \\
\text { ежедневных донесений } \\
\text { (докладов) }\end{array}$ & $\begin{array}{l}\text { В среднем на } \\
\text { одного } \\
\text { специалиста }\end{array}$ & 5 & 143 & 30 & $9,95 \%$ \\
\hline \multicolumn{4}{|c|}{ Ежедневные донесения в сутки подготовка } & $\mathbf{3 a}$ & 2,4 & часа \\
\hline
\end{tabular}

\section{ОЦЕНКА ЭФФЕКТИВНОСТИ}

На шестом этапе выполнена оценка влияния оригинальных алгоритмов, примененных в интерфейсах «АРМ - Администратор», на эффективность взаимодействия с АРМ руководителей и специалистов подразделений ОДС при выполнении задач анализа, планирования, прогнозирования, контроля, учета и оперативного реагирования в процессе подготовки документов. Алгоритмы, примененные в аналогах информационных блоков АРМ, позволяют: объединять и контролировать данные подготовленные нескольки- ми специалистами, передавать информацию между разными АРМ, прогнозировать вероятность, анализировать факты и результаты предупреждения возможного возникновения ЧС (происшествий), пожаров по заданным параметрам, выполнять автоматическую генерацию реквизитов документов, фиксировать и контролировать время готовности документов, обеспечивать непосредственный доступ к необходимым документам и к справочной информации. 


\section{А. Л. Попов}

\section{ЗАКЛЮЧЕНИЕ}

В результате внедрения результатов интеллектуальной и технической поддержки деятельности специалистов подразделений ОДС регионального ЦУКС уменьшились затраты времени на одного специалиста ОДС и существенно улучшились показатели процесса подготовки документов специалистами ОДС. Исходя из представленных в табл. 2 показателей сделан вывод, что в результате снижения трудоемкости примерно на 50 $\%$ реально специалист подразделения ОДС ЦУКС в течение суточного дежурства увеличил собственный ресурс и улучшил качество подготовки документов в процессе реагирования на регистрируемые события: с 9 до 21 ЧС (происшествия) или с 11 до 24 пожаров.

Интеллектуальная и техническая поддержка деятельности руководителей и специалистов подразделений ОДС регионального ЦУКС реализованная на «АРМ - Администратор» в составе СУБД «АРМы ОДС» обеспечила организацию автоматизированного процесса подготовки отчетных документов при возникновении ЧС (происшествий), пожаров и функциональных документов в режиме повседневной деятельности, актуализацию данных, возможность доработки действующих и разработки «новых» АРМ ОДС ЦУКС.

\section{СПИСОК ЛИТЕРАТУРЫ}

1. Попов, А. Л. Практика автоматизации процесса подготовки документов оперативной дежурной смены центра управления в кризисных ситуациях / А. Л. Попов // Современные технологии обеспечения гражданской обороны и ликвидации последствий чрезвычайных ситуаций : сб. мат. Х Всерос. научно-практической конф. (Воронеж, 18 апреля 2019 г.). - Воронеж, 2019. - С. 320-321.

2. Попов, А. Л. Автоматизация процесса подготовки документов оперативной дежурной сменой Центра управления в кризисных ситуациях / А. Л. Попов // Современные проблемы гражданской защиты (Проблемы анализа риска) (ВЕСТНИК ВОРОНЕЖСКОГО
ИНСТИТУТА ГПС МЧС РОССИИ), - 2019. № 2. - С. 5-17.

3. Методики оценки рисков чрезвычайных ситуаций и нормативы приемлемого риска чрезвычайных ситуаций / В. А. Акимов [и др.] // Проблемы анализа риска. - 2007. Т. 4, № 4. - С. 368-377.

4. Антюхов, В. И. Алгоритмизация деятельности должностных лиц центров управления в кризисных ситуациях МЧС России / В. И. Антюхов, Н. В. Остудин // Технологии техносферной безопасности. - 2017. - № 2 (42). - C. 10-15.

5. Антюхов, В. И. Методика выявления и анализа проблемных вопросов в деятельности должностных лиц ЦУКС МЧС России / В. И. Антюхов, Н. В. Остудин // Вестник Санкт-Петербургского университета ГПС МЧС России. - 2016. - № 1. - С. 97-106.

6. Попов, П. А. Наставление по организации деятельности центров управления в кризисных ситуациях МЧС России. М. : НЦУКС МЧС России, 2012. - 159 с.

7. Модель информационной поддержки принятия решения при оценке деятельности сотрудников МЧС России / В. А. Онов [и др.] // Пожаровзрывобезопасность. - 2017. - Т. 26, № 2. - C. 5-13.

8. Сосунов, И. В. Нормативная и методологическая база анализа риска ЧС: реальность и перспективы / И. В. Сосунов // Технологии гражданской безопасности. - 2010. - Т. 7, № 3 (25). - C. 52-57.

9. Остудин, Н. В. Модели и алгоритмы информационно-аналитической поддержки антикризисного управления: автореф. дис. канд. техн. наук. - СПб. : УГПС МЧС России, 2018. - 24 c.

10. Антюхов, В. И. Методика выявления перечня задач интеллектуальной поддержки деятельности должностных лиц центров управления в кризисных ситуациях МЧС России / В. И. Антюхов, Н. В. Остудин, А. В. Сорока // Вестник Санкт-Петербургского университета ГПС МЧС России. - 2016. - № 4. C. 63-76.

11. Попов, А. Л. Применение функций прогнозирования вероятности и анализа фактов возникновения происшествий, чрезвычай- 
ных ситуаций и пожаров в оперативной дежурной смене центра управления в кризисных ситуациях / А. Л. Попов // Современные технологии обеспечения гражданской обороны и ликвидации последствий чрезвычайных ситуаций: сб. мат. X Всерос. научно-практической конф. (Воронеж, 18 апреля 2019 г.). Воронеж, 2019. - С. 321-323.

12. Попов, А. Л. Прогнозирование вероятности и анализ фактов возникновения происшествий (ЧС) и пожаров в ОДС ЦУКС / А. Л. Попов // Проблемы безопасности и чрезвычайных ситуаций. - 2019. - № 3. - С. 86-93.

13. Попов, А. Л. Опыт внедрения и развития системы управления базами данных автоматизированных рабочих мест оперативной дежурной смены центра управления в кризисных ситуациях / А. Л. Попов // Современные технологии обеспечения гражданской обороны и ликвидации последствий чрезвычайных ситуаций: сб. мат. Х Всерос. научно-практической конф. (Воронеж, 18 апреля 2019 г.). - Воронеж, 2019. - С. 318-319.

14. Щепилов, И. А. Анализ системы управления ЦУКС ГУ МЧС России по Нижегородской области при возникновении чрезвычай- ной ситуации / И. А. Щепилов // Технологии техносферной безопасности. - 2016. - № 5. C. $178-187$.

15. Рыженко, А. А. Автоматизация документооборота Центра управления в кризисных ситуациях с использованием платформы «1С:ПРЕДПРИЯТИЕ 8» / А. А. Рыженко, Н. Ю. Рыженко // Сборник трудов конференции ФГБОУ ВО Академия ГПС МЧС России, г. Москва. - 2019. - С. 64-67.

16. А.с. 2018621459 Российская Федерация, № 2018621203. База данных автоматизированного рабочего места «Комплексной системы экстренного оповещения населения» «Комплексной информационной системы мониторинга и управления силами и средствами МЧС г. Москвы» / Ражников С. В., Попов А. Л., Бутузов С. Ю.; заявл. 27.08.2018; опубл. 06.09.2018, ФИПС. - 1 с.

17. Антюхов, В. И. Моделирование процесса интеллектуальной поддержки деятельности должностных лиц центров управления в кризисных ситуациях МЧС России / В. И. Антюхов, Н. В. Остудин // Вестник Санкт-Петербургского университета ГПС МЧС России. - 2017. - № 2. - С. 78-94.

Попов Александр Леонидович - главный специалист Государственного казенного учреждения города Москвы «Пожарно-спасательный центр», e-mail: pal_300353@mail.ru

\title{
AUTOMATED WORKPLACE OF THE ADMINISTRATOR OF THE OPERATIONAL DUTY SHIFT OF THE CONTROL CENTER IN CRISIS SITUATIONS
}

\author{
A. L. Popov \\ State institution of the city of Moscow «Fire and rescue center»
}

\begin{abstract}
Annotation. The article is devoted to the implementation of the process of gradual transition to intellectual technical support of the operational duty shift of the regional control Center in crisis situations of the Russian emergencies Ministry. The article introduces the idea of the development of the automatized working place of the administrator of the operational duty shift. Software modules of information blocks interfaces are developed. The original author's algorithms are used: combining data, generating details of documents, transferring information between automated workplaces, fixing and controlling the time of readiness of documents, access to the necessary reference information, forecasting the probability of risk, analysis of facts and results of prevention of possible emergencies (accidents) and fires.

Keywords: crisis management, intelligent support, database management system, technical support, emergency, crisis management center.
\end{abstract}

Popov Alexander L. - chief specialist of the state state institution of the city of Moscow «Fire and rescue center», e-mail: pal_300353@mail.ru 